\title{
SIMULATION OF STRESS PATHS DERIVED FROM FEM ANALYSIS IN TRIAXIAL TESTS
}

\author{
M. KOWALSKA ${ }^{1}$
}

\begin{abstract}
Reliable estimation of geotechnical parameters is often based on reconstruction of a complete loading process of subsoil on a specimen in laboratory tests. Unfortunately laboratory equipment available in many laboratories is sometimes limited to just a triaxial apparatus - the use of which generates difficulties whenever a non-axisymmetric problem is analysed.

The author suggests two simple operations that may be done to improve the quality of simulation in triaxial tests. The first one is based on the use of triaxial extension along the segments of the stress path p'-q- $\theta$ for which the Lode's angle values are positive. The second one consists in a modification of the equivalent stress value in such a way that the current stress level in the specimen complies with results of FEM analysis.
\end{abstract}

Key words: Laboratory tests, numerical modelling, stress path, triaxial test

\section{INTRODUCTION}

The influence of a loading history on soil behaviour (and consequently on geotechnical parameters) has been documented in numerous research papers e.g. by Burland [1], Atkinson et al. [2] or Kowalska [3]. Thus even more important becomes the use of the stress path method (Lambe [4], Lambe and Marr [5], Davis and Poulos [6]) or the loading path method (Gryczmański and Kowalska [7], Kowalska [8]) in analyses of real 'soil - structure' interaction problems. Their basic requirement is a possibly real simulation of loading paths in the subsoil considered. This is usually done in laboratory conditions as they enable full control of stress or strain in soil specimens, in contrast to in situ tests. The loading paths represent then some specific points (or 'average elements') of the subsoil.

The most common way of the loading path presentation is in the form of stress paths, which most often (also in formulations of constitutive models) are presented as the stress tensor invariants: mean effective stress $p$ ', equivalent stress $q$ and Lode's angle $\theta$ :

$1 \mathrm{PhD}$, MSc, Silesian University of Technology, Faculty of Civil Engineering, Department of Geotechnics, ul. Akademicka 5, 44-100 Gliwice, POLAND, magdalena.kowalska@polsl.pl 


$$
\begin{gathered}
p^{\prime}=\frac{1}{3}\left(\sigma_{1}^{\prime}+\sigma_{2}^{\prime}+\sigma_{3}^{\prime}\right) \\
q=\frac{1}{\sqrt{2}}\left[\left(\sigma_{1}^{\prime}-\sigma_{2}^{\prime}\right)^{2}+\left(\sigma_{2}^{\prime}-\sigma_{3}^{\prime}\right)^{2}+\left(\sigma_{3}^{\prime}-\sigma_{1}^{\prime}\right)^{2}\right]^{\frac{1}{2}} \\
\theta^{\prime}=\arcsin \left\{\frac{1}{\sqrt{2}} \frac{2 \sigma_{2}^{\prime}-\sigma_{1}^{\prime}-\sigma_{3}^{\prime}}{\left[\left(\sigma_{1}^{\prime}-\sigma_{2}^{\prime}\right)^{2}+\left(\sigma_{2}^{\prime}-\sigma_{3}^{\prime}\right)^{2}+\left(\sigma_{3}^{\prime}-\sigma_{1}^{\prime}\right)^{2}\right]^{\frac{1}{2}}}\right\},-\frac{\pi}{6}<\theta^{\prime}<\frac{\pi}{6}
\end{gathered}
$$

where $\sigma_{1}^{\prime}, \sigma_{2}^{\prime}$ and $\sigma_{3}^{\prime}$ are respectively: effective major, medium and minor principal stress $\left(\sigma_{1}^{\prime}>\sigma_{2}^{\prime}>\sigma_{3}^{\prime}\right)$.

The values of the stress tensor invariants are relatively easy to obtain in a numerical analysis, e.g. with the use of the finite element method (FEM). At the current level of constitutive modelling the stress paths may be determined based on models that are much more sophisticated than elastic, e.g. critical state type models, thus enabling far better representation of real (observed) soil behaviour, without much greater work effort.

In the author's opinion the greatest obstacle in popularization of the stress or loading path methods are the limitations of the laboratory equipment.

So far, the full control of all the three principal stresses (magnitudes and rotations) in laboratory conditions is possible practically only in a hollow cylinder apparatus, which, unfortunately is in possession of only a few university centres and still is not free from some technical limitations, like: non-uniformity of stresses or cumbersome preparation of specimens (Hight et al. [9], Saada [10]).

The triaxial apparatus remains most available laboratory equipment. Despite of the great technical development (Coop and Schnaid [11]) and introduction of automatic stress path control systems, the conventional triaxial apparatus is the one in which only axisymmetric state of stress may be applied to a soil specimen. Such conditions are valid just for a limited number of real cases, like: chimney footings or foundations of circular tanks and even then - just at the points situated under the centres of these foundations and only under axial or uniformly distributed loads. Precise simulation of soil behaviour at other set of points (far from the axis) or in case of any other 'soil structure' interaction (strip footings, retaining walls, etc.) in the triaxial apparatus is practically impossible. However, if a laboratory is equipped only in a triaxial apparatus with stress path control system, a soil testing procedure that follows the stress paths at least resembling the practical case, even if they are reduced to axisymmetric conditions, is still much more reliable in terms of soil behaviour prognosis, than an experiment in which the loading history and boundary value problem is not allowed for at all. 
To enable better simulation of the current stress level (defined as a fraction of strength mobilized) in a triaxial test, there can be simple modifications done to the value of the equivalent stress $q$ obtained as the result of FEM analysis with the use of critical state models - either by enforcing extension or by taking into account the medium principal stress value while keeping compressive conditions. These corrections are the subject of this paper.

\section{LiMITATIONS OF TRIAXIAL APPARATUS}

In a triaxial apparatus a stress path cannot leave the compression plane $\Pi: \sigma_{2}^{\prime}=\sigma_{3}{ }_{3}$ or the extension plane $\Omega: \sigma^{\prime}{ }_{2}=\sigma_{1}^{\prime}$, for which the Lode's angle is constant and equal to $-30^{\circ}$ or $30^{\circ}$ respectively. Additionally, passing from one plane to another is feasible only when the equivalent stress $q=0 \mathrm{kPa}$ (Fig. 1).

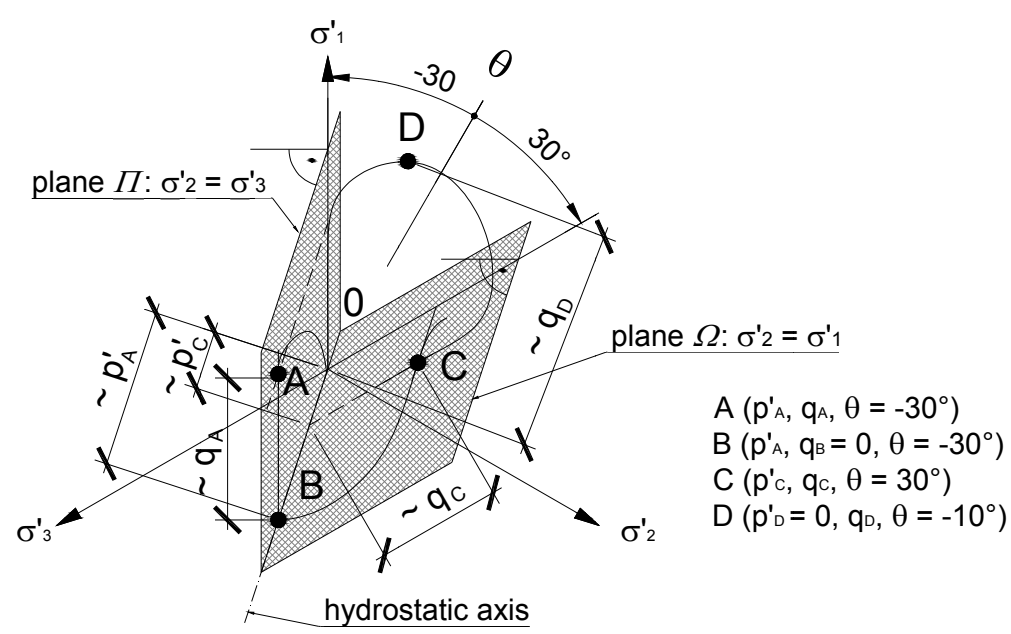

Fig. 1. Stress planes in a triaxial test: $\Pi$ and $\Omega$. Stress paths: $0 \mathrm{ABC}-$ feasible; $0 \mathrm{DC}-$ unfeasible.

As the medium principal stress and Lode's angle must be ignored, because there is no possibility to control them during the test, the equivalent stress $q$ is usually reduced to the simpler form:

- in triaxial compression:

$$
q=\sigma_{1}-\sigma_{3}=\left(\text { cell.pressure }+\frac{|P|}{A}\right)-(\text { cell.pressure })=\frac{|P|}{A}
$$


- and in triaxial extension:

$$
q=\sigma_{3}-\sigma_{1}=\left(\text { cell.pressure }-\frac{|P|}{A}\right)-(\text { cell.pressure })=-\frac{|P|}{A},
$$

where $|P|$ is the absolute value of the axial force applied to the specimen with cross section area equal to $A$. Thus, as a rule, the triaxial extension on $p^{\prime}-q$ graphs is presented with negative values of $q$, even though according to the definition (2), as a square root, it should never be negative.

If the stress path $p^{\prime}-q$ at a chosen point of a subsoil analysed is obtained as a result of FEM analysis and in the software the $q$ is defined as (2) and therefore - always positive, there appears a problem: when the triaxial extension is to be applied in the test?

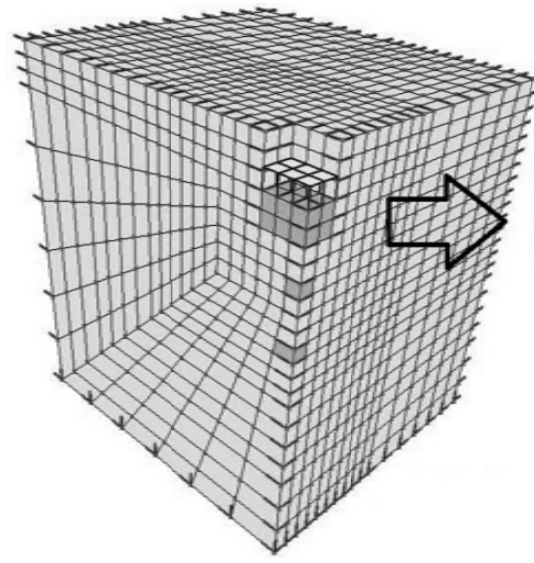

a)

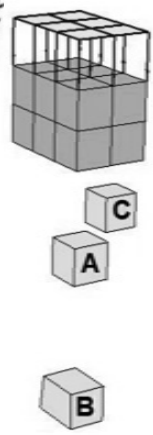

b)

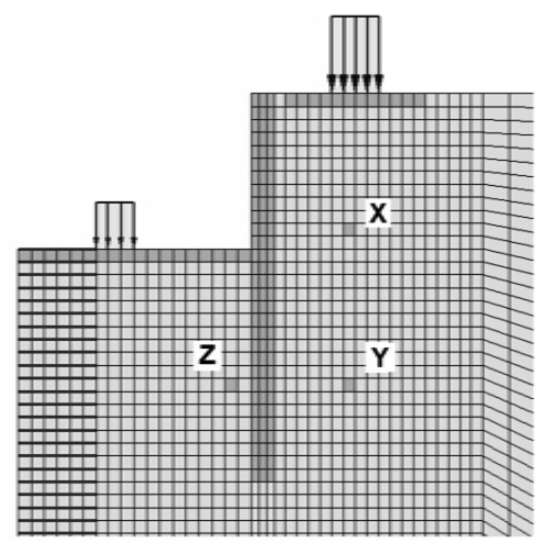

Fig. 2. Numerical model of the rectangular footing a) and retaining wall b) with the selected points specified.

Let's analyse two simple cases: a cuboid footing and a retaining wall modelled in Z_Soil.PC FEM program. The subsoil with parameters corresponding to Speswhite kaolin is described with the Modified Cam Clay model (Roscoe and Burland [12]) improved by van Eekelen's correction (van Eekelen [13], Zimmermann et al. [14]) applying to the originally conical critical state surface. The loading process in both cases includes: geological history (accumulation and erosion) with the maximum load of $120 \mathrm{kPa}$, excavation, execution of the structure, exploitation load $(1000 \mathrm{kPa}$ on the footing and behind the wall and $600 \mathrm{kPa}$ in front of the wall). Three points in the subsoil are selected in both cases: A (central, depth: $2.25 \mathrm{~m}$ ), B (central, depth: $3.45 \mathrm{~m}$ ), C (under corner, depth: $2.25 \mathrm{~m}$ ) and $\mathrm{X}$ (behind the wall, depth: $3.5 \mathrm{~m}$ ), Y (behind the wall, depth: 
$7.5 \mathrm{~m}$ ), Z (in front of the wall, depth: $7.5 \mathrm{~m}$ ) respectively. The numerical models are presented in Fig. 2 and the stress paths representing all the points - in Fig. 3 and Fig. 4.
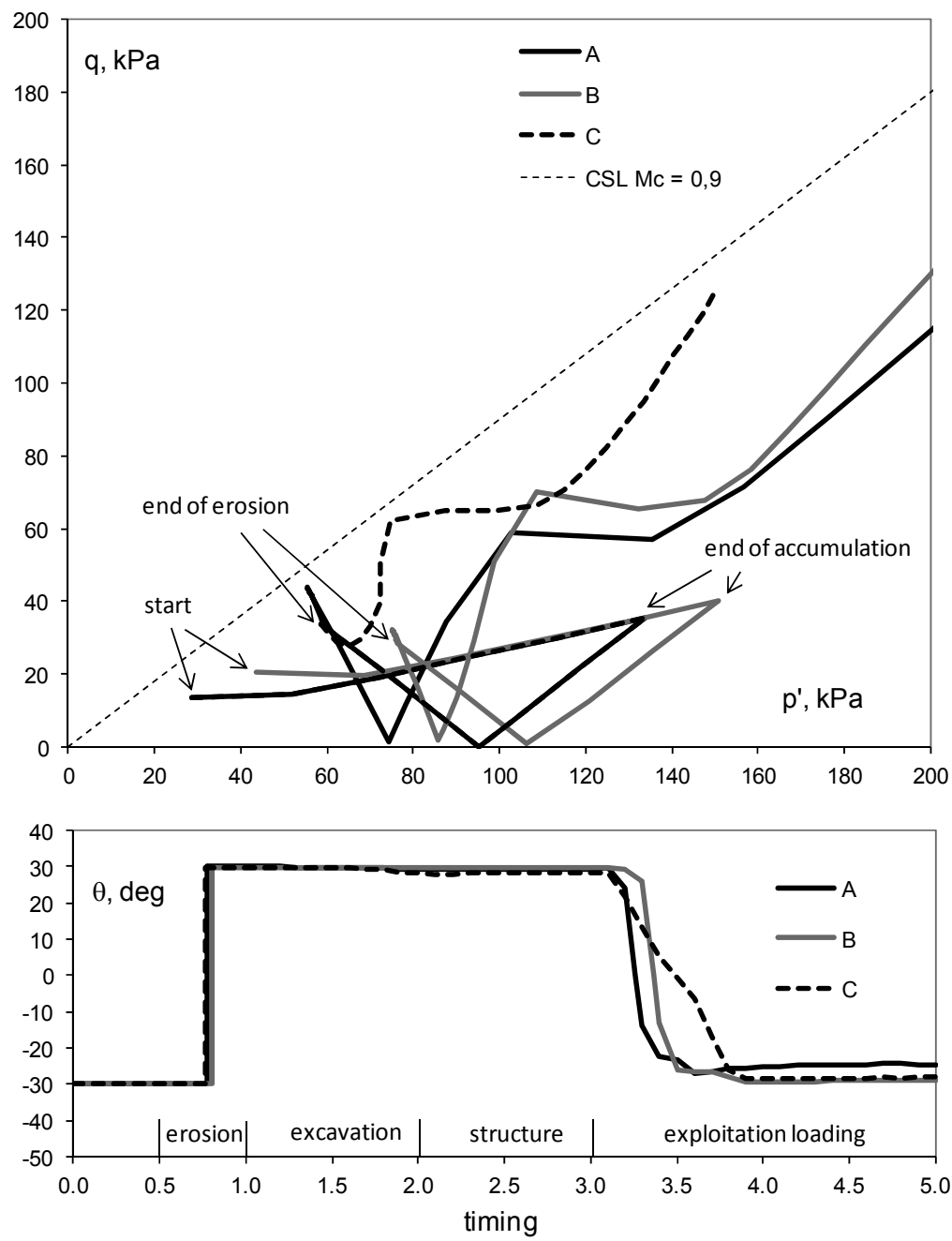

Fig. 3. Stress paths at points A, B, C under cuboid footing, with timing.

As can be seen, the processes of accumulation and erosion might be easily simulated in the triaxial test, because the Lode's angle equals either $-30^{\circ}$ or $30^{\circ}$ and at the time it changes (rapidly) from negative to positive the equivalent stress $q$ equals $0 \mathrm{kPa}$. During the next loading stages the stress paths under the footing behave differently than in the proximity of the retaining wall. The stress paths at the points $\mathrm{A}$ and $\mathrm{B}$, which are located under the centre of the pad foundation, could be simulated in the triaxial appa- 
ratus again, cause during the exploitation loading the Lode's angle changes again quite rapidly from $30^{\circ}$ to $-30^{\circ}$ at $q$ value close to $0 \mathrm{kPa}$. However, in the case of point $\mathrm{C}$ this change is much slower and $q$ value does not approach zero. Such a stress path resembles the stress path CD0 in Fig. 1 - during the exploitation loading it goes from the triaxial extension plane $\Omega$ to the compression triaxial plane $\Pi$, but in the 'meantime' it crosses the stress space between these two planes. At the points X, Y, Z the change in the Lode's angle values is even more erratic and the stress paths do not reach the compression plane again at all.
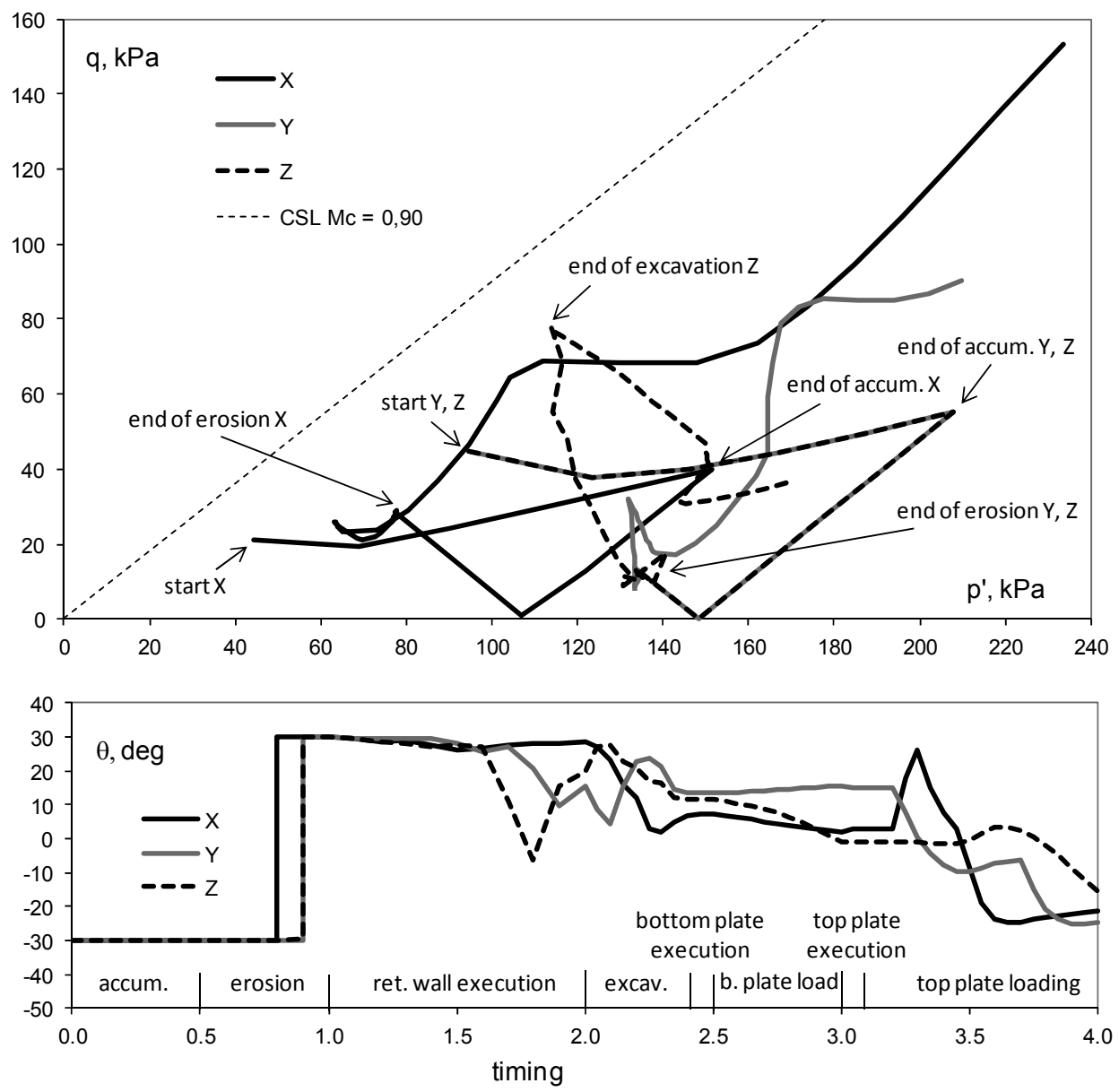

Fig. 4. Stress paths at points $\mathrm{X}, \mathrm{Y}, \mathrm{Z}$ near the retaining wall, with timing. 


\section{Negative Value of EQuivalent StREss}

The stress paths at points A and B could be easily presented with the negative values of $q$ wherever the Lode's angle equals $30^{\circ}$, giving the result shown in Fig. 5. The same procedure for the stress path at point $\mathrm{C}$ means that it should be longer by an additional segment (Fig. 3), which does not correspond to any physical action in the numerical model. On the other hand, thanks to this operation it is possible to simulate the process of erosion in much realistic way - without any artificial changes in the stress path direction ('bouncing' from the hydrostatic axis), which would unrealistically influence the soil response (strain path and soil stiffness). It is also possible to take into account the observed non-axisymmetrical shape of the yield and boundary surfaces - wider in compression and narrower in extension (Coulomb [15], Mohr [16], Lade and Duncan [17], van Eekelen [13], Menetrey and Willam [18]), without any special attempts.

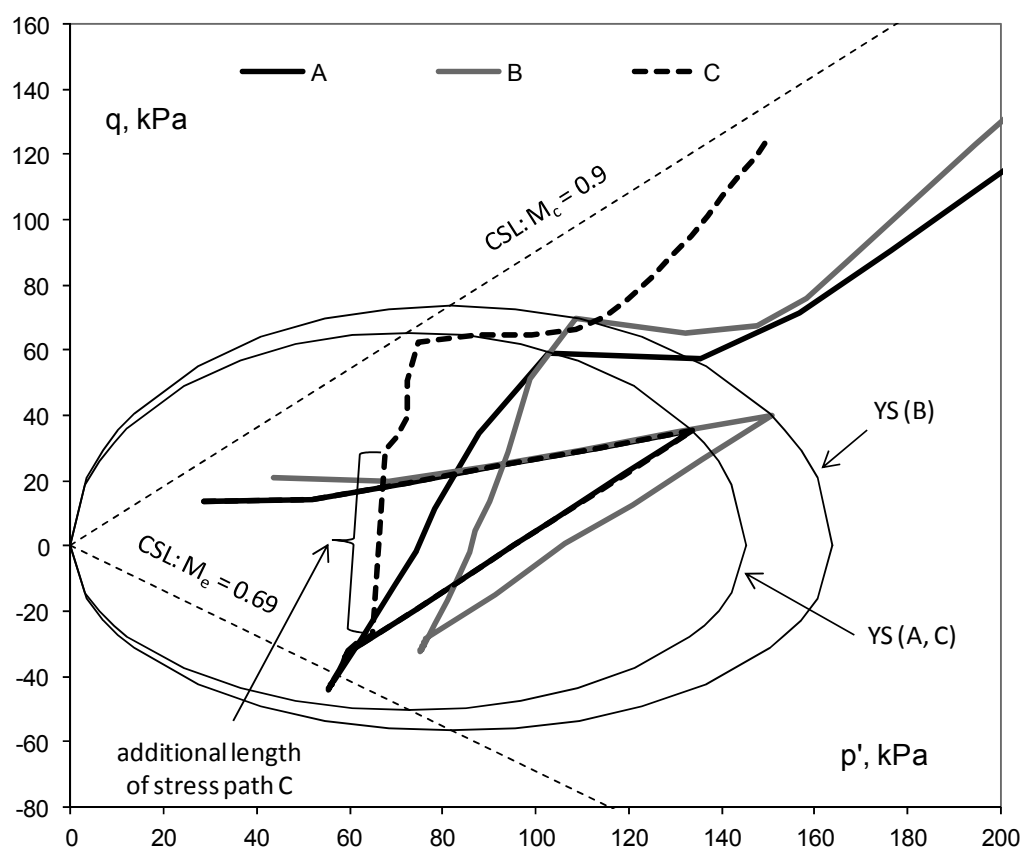

Fig. 5. Stress paths p'-q in the case of cuboid footing; with positive and negative q. YS - yield surface at the end of geological processes, CSL - critical state line defined with $M=0.9$ in compression and $\mathrm{M}=0.69$ in extension.

Such a manipulation in the case of points $\mathrm{X}, \mathrm{Y}, \mathrm{Z}$, where plane stress conditions dominate, could be yet called a huge over-simplification. In the author's opinion it is better to project the three-dimensional stress path $p^{\prime}-q-\theta$ on the triaxial compression plane (and keep the positive values of $q$ ), but to take into account the distance of the 
particular stress states from the failure surface, defined as stress level, and thus also the Lode's angle, in form of a modification of the equivalent stress value.

\section{Modification of Equivalent Stress value}

Based on the van Eekelen's proposal applied in the Z_Soil.PC program, the inclination of the critical state line $M$ in the Modified Cam Clay model changes with the Lode's angle according to the formula (6):

(6) $M=M_{c} r(\theta)$

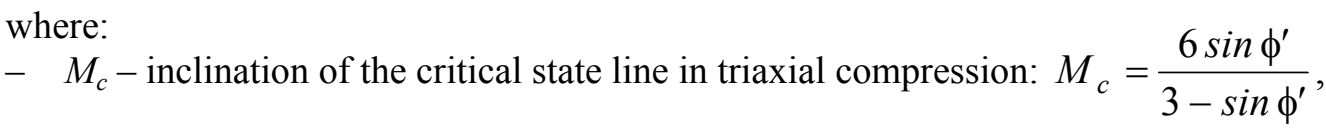
where: $\phi^{\prime}-$ internal angle of friction in triaxial compression,

$-r(\theta)=\left(\frac{1+\alpha \sin (3 \theta)}{1-\alpha}\right)^{n}$, where: $\alpha=\frac{k^{\frac{1}{n}}-1}{k^{\frac{1}{n}}+1} \leq 0.7925, k=\frac{3-\sin \phi}{3+\sin \phi}, n=-0.229$.

The equivalent stress at failure $q_{f}$ is then defined depending on the history of maximum loading as:

(7) $q_{f}=M_{c} r(\theta) p^{\prime}-$ in normal consolidation conditions or:

(8) $q_{f}=\sqrt{M_{c}^{2} r^{2}(\theta) p^{\prime}\left(p_{c}^{\prime}-p^{\prime}\right)}$ in case of preconsolidation.

According to formula (6), the value $M=0.90=M_{c}$ obtained for Speswhite kaolin in triaxial compression transforms into $M=0.69=M_{e}$ in triaxial extension and yield surfaces become non-axisymmetrical - like it is presented in Fig. 5. This means, that if the stress level, defined as (9):

$$
S L=\frac{q}{q_{f}},
$$

and determined in the numerical analysis, is to be simulated during the laboratory test, then to stay at the compression plane, the equivalent stress should be modified to:

$$
q_{\text {mod }}=\frac{q}{r(\theta)} .
$$


The influence of this modification on the shape of the stress paths may be observed in Fig. 6, where two exemplary stress paths for points $\mathrm{C}$ and $\mathrm{Z}$ are presented.
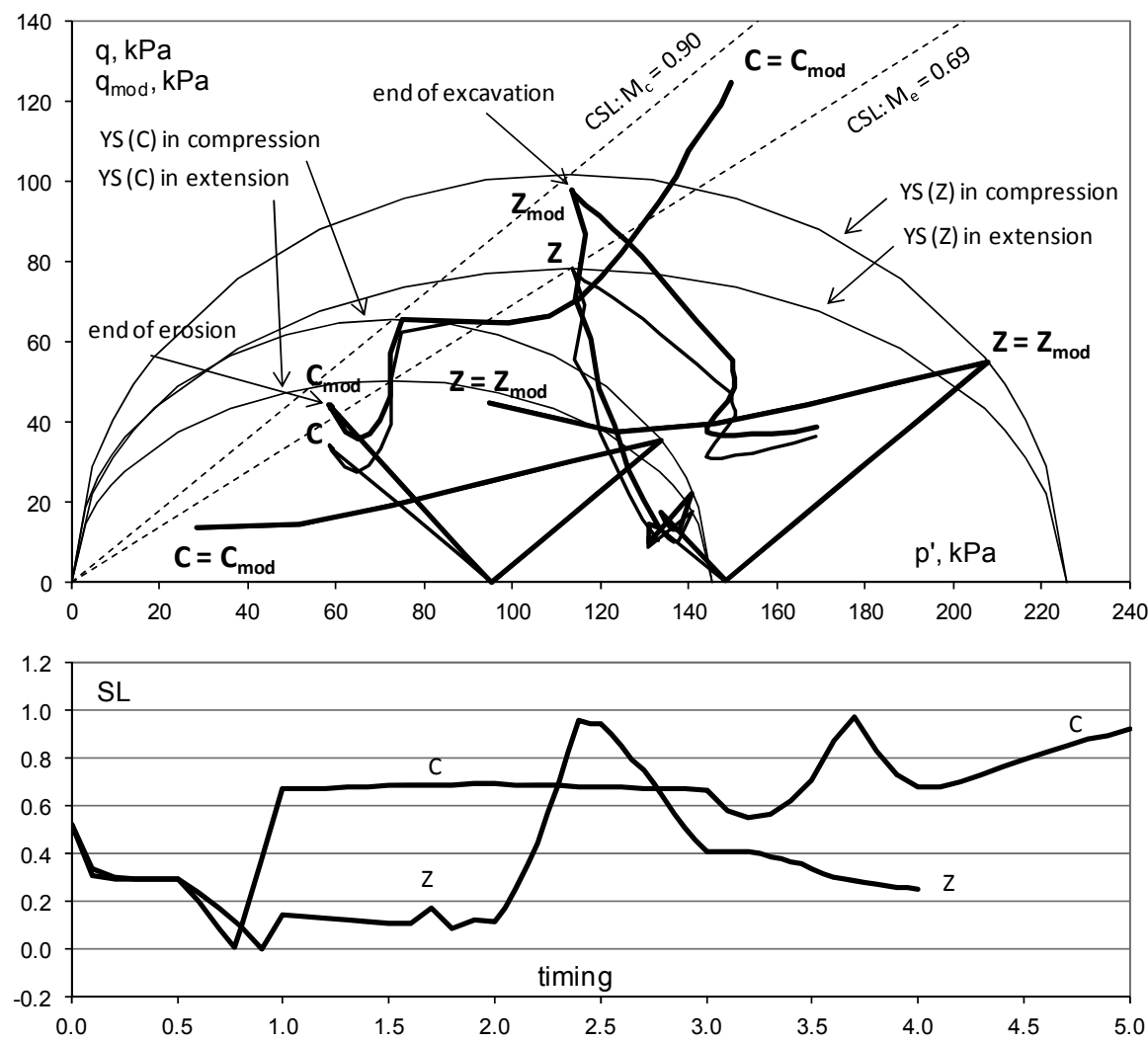

Fig. 6. Stress paths at points $\mathrm{X}, \mathrm{Y}, \mathrm{Z}$ near the retaining wall, with timing.

The differences in the shape of the stress paths $p^{\prime}-q$ and $p^{\prime}-q_{\text {mod }}$ show up wherever the Lode's angle deviates from $-30^{\circ}$. So, in the case of point $\mathrm{C}$ it is the most noticeable during erosion, starting from the stress state where $q=0$, later both stress paths coincide. While in the case of point $Z$, the modified stress path deviates from the initial shape along its whole length, starting again from the point where $q=0$. The biggest difference is at the stress state corresponding to the end of excavation ('time' 2.4), where at $\theta=12^{\circ}$ the stress level is close to unity ( $\left.\mathrm{SL}=0.96\right)$, which denotes failure. Without the modification the stress level would be equal to only 0.69 and so the strain of soil observed in a triaxial test would probably be far too small - not corresponding to the pre-failure situation. 


\section{Conclusions}

Limitations of soil testing in triaxial apparatus in terms of simulation of any stress path $p^{\prime}-q-\theta$ derived from numerical analysis have been presented. Two simple corrections of the equivalent stress $q$ value are suggested enabling to maintain the numerically calculated stress level during triaxial testing. The first one consists in enforcing triaxial extension conditions (horizontal stress $>$ vertical stress) and so negative value of $q$, wherever the Lode's angle value is changing from $-30^{\circ}$ to $30^{\circ}$ provided that $q=0 \mathrm{kPa}$ at the moment. The second one consists in applying a correction on the $q$ value dependent on the current Lode's angle and may be used practically for any stress path determined with the use of critical state models, keeping though in mind, that this modification may give non-realistic strain readings wherever the stress path is 'bouncing' from the hydrostatic axis.

These modifications give the possibility to simulate the 'real' soil strength mobilization but of course they do not constitute the universal remedy for the triaxial apparatus limitations. It might be said that they provide a 'golden mean' solution whenever non-axisymmetric stress conditions are to be simulated and the triaxial apparatus is the only available laboratory equipment.

\section{REFERENCES}

1. J.B. Burland, Ninth Laurits Bjerrum Memorial Lecture: "Small is beautiful" - the stiffness of soils at small strains, Canadian Geotechnical Journal, 26, 499-516, 1989.

2. J.H. Atkinson, D. Richardson, S.E. Stallebrass, Effect of recent stress history on the stiffness of overconsolidated soil, Geotechnique, 40, 4, 531-540, 1990.

3. M. KoWALSKA, Influence of loading history and boundary conditions on parameters of soil constitutive models, Studia Geotechnica et Mechanica, XXXIV, 1, 15-34, 2012.

4. T.W. Lambe, Stress Path Method, Journal of Soil Mechanics and Foundations Division Proc of ASCE, 93, SM6, 309-331, 1967.

5. T.W. Lambe, W.A. MarR, Stress Path Method: Second Edition Journal of the Geotechnical Engineering Division, ASCE, 105, 6, 727-738, 1979.

6. E.H. Davis, H.G. Poulos, The use of elastic theory for settlement prediction under three-dimensional conditions, Geotechnique, 18, 1, 67-91, 1968.

7. M. Gryczmański, M. Kowalska, Evaluation of geotechnical parameters in modern laboratory tests accounting for loading paths, Studia Geotechnica et Mechanica, 29, 1-2, 47-54, 2007.

8. M. Kowalska, Parametric identification of soil models in geotechnical problems. (in Polish). $\mathrm{PhD}$ Thesis, Silesian University of Technology, Gliwice, 2009.

9. D.W. Hight, A. Gens, M.J. Symes, The development of a new hollow cylinder apparatus for investigating the effects of principal stress rotation in soils, Geotechnique, 33, 4, 355-383, 1983.

10. A.S. SAadA, State-of-the-Art Paper: Hollow Cylinder Torsional Devices: Their Advantages and Limitations In: Donaghe RT, Chaney RC, Silver ML (eds) Advanced Triaxial Testing of Soil and Rock. American Society for Testing and Materials, Philadelphia, 766-795. doi:10.1520/STP977-EB, 1988.

11. M. Coop, F. Schnaid, Contributions to Geotechnique 1948-2008: Laboratory and field testing, Geotechnique, 58, 5, 423-428, 2008. 
12. K.H. Roscoe, J.B. Burland, On the generalized stress - strain behaviour of 'wet clay'. In: Heyman J, Leckie FA (eds) Engineering plasticity. Cambridge University Pres, Cambridge, 535-609, 1968.

13. H.A.M. van Eekelen, Isotropic Yield Surfaces in Three Dimensions for Use in Soil Mechanics, International Journal for Numerical and Analytical Methods in Geomechanics, 4, 89-101, 1980.

14. T. Zimmermann, A. Truty, A. Urbański, K. Podleś, Z_SOIL.PC 2007 manual. Theory 2007.

15. C.A. Coulomb, Essai sur une application des regeles de maximis $\&$ minimis a quelques problemes de statique relatifs a l'architecture, Mem de Math et de Phys, presentes a l'Acad Roy des Sci, 7, 343-382, 1773.

16. О. Монг, Welche Umstände bedingen die Elastizitätsgrenze und den Bruch eines Materiales?, Zeitschrift des Vereines Deutscher Ingenieure, 44, 1-12, 1900.

17. P.V. LADE, J.M. DunCAN, Elastoplastic stress-strain theory for cohesionless soil, J Geotech Eng, ASCE, 101, GT10, 1037-1053, 1975.

18. P. Menetrey, K.J. Willam, Triaxial Failure Criterion for Concrete and its Generalization, Structural Journal, 92, 3, 311-318, 1995. 